\title{
JESS FIXATOR FOR METACARPAL AND PHALANGEAL FRACTURE
}

\author{
Mishra AK, Adhikari V, Chalise P, Shrestha P, Singh RP
}

Department of Orthopaedics, Nepal Medical College Teaching Hospital, Attarkhel, Gokarneshwor-8, Kathmandu, Nepal

\begin{abstract}
The fractures of metacarpal and phalanges of the hand are the most common injury encountered in emergency department. Most often these injuries are neglected as minor injuries and later on develops a functional limit of the hand. Joshi's external stabilizing system (JESS) fixator based on the principle of ligamentotaxis, stabilize the unstable and intraarticular fractures of metacarpal and phalangeal and also provides an environment for rapid soft tissue healing without further damaging the microvascular circulation. The study includes total number of 38 patients with a diagnosis of fracture of Metacarpal and phalanx of hand admitted in Nepal Medical college and Teaching Hospital who were treated with JESS fixator. The functional outcome after the removal of JESS fixator was assessed by calculating American Society for Surgery of Hand and Total Active flexion (ASSH TAF). Among the 38 patients, all fractures went to union with an average union period of 6 weeks. The mean period of treatment for metacarpal fractures was12 weeks and for phalangeal fractures 16 weeks by which time patients regained full functional activity of hand and returned back to their respective works. The functional outcome assessed by ASSH-TAF score was excellent in 28 patients, good in 10 patients and none of them had a poor result. The complication was seen in $9(23.68 \%)$ cases, superficial pin tract infection and K Wire Loosening. JESS fixator is cheap, easily available and less technically demanding, provides with an effective treatment for the metacarpal and phalanges fracture, as it provides adequate stability that allows early rehabilitation with soft tissue care and has got a good functional outcome
\end{abstract}

\section{KEYWORDS}

American Society for Surgery of Hand and Total Active flexion (ASSH TAF), Fixator, Joshi's external stabilizing system (JESS), Metacarpal and Phalangeal fracture

\section{CORRESPONDING AUTHOR}

Dr. Anil Kumar Mishra,

Associate Professor, Department of Orthopaedics,

Nepal Medical College Teaching Hospital,

Attarkhel, Gokarneshwor-8, Kathmandu, Nepal,

Email: dranilmishra3@gmail.com 


\section{INTRODUCTION}

The fractures of metacarpal and phalanges of the hand are the most common injury with the prevalence of $10-30 \%$ of all fractures. ${ }^{1,2}$ The incidence of hand injury is seen more during the young age group with male dominance. ${ }^{3}$ These hand fractures are commonly encountered in emergency department, due to multiple causes like road traffic accidents, machine injury, crush injury, assaults and explosion based injury. ${ }^{4,5}$ Most often these injuries are neglected as minor injuries and later on develops a functional limit of the hand. ${ }^{6}$ The optimal goal of the treatment of hand injuries are healing of wound, bony union and most important restoration of the functions.

The hand injury is mainly treated conservatively with plaster and splints but surgical intervention is required in unstable, communited, intraarticular fractures and in open fractures for soft tissue and bony healing in optimal position with early range of movement of joints to preserve the functions of the hand. ${ }^{7,8}$ There are different surgical techniques with various fixation devises having their own merit and demerit such as Kirschner (K) wires fixation, mini plates and external fixator application used to depend upon the fracture pattern and soft tissue condition.

The external fixator, which works on the principle of ligamentotaxis is an effective and useful devise for the fixation especially in intraarticular, displaced communited fracture and open fracture, where we have to deal with both bony and soft tissue injury.

Joshi's external stabilizing system (JESS) fixator based on the principle of ligamentotaxis, stabilizes the unstable and intraarticular fractures with the use of thin smooth K-wires placed away from the injury site, which is attached to rods for a stable configuration and also provides an environment for rapid soft tissue healing without further damaging the microvascular circulation with less risk of infection, makes nursing care easy in open fractures. The early rehabilitation can be done which helps to prevent joint stiffness, which is

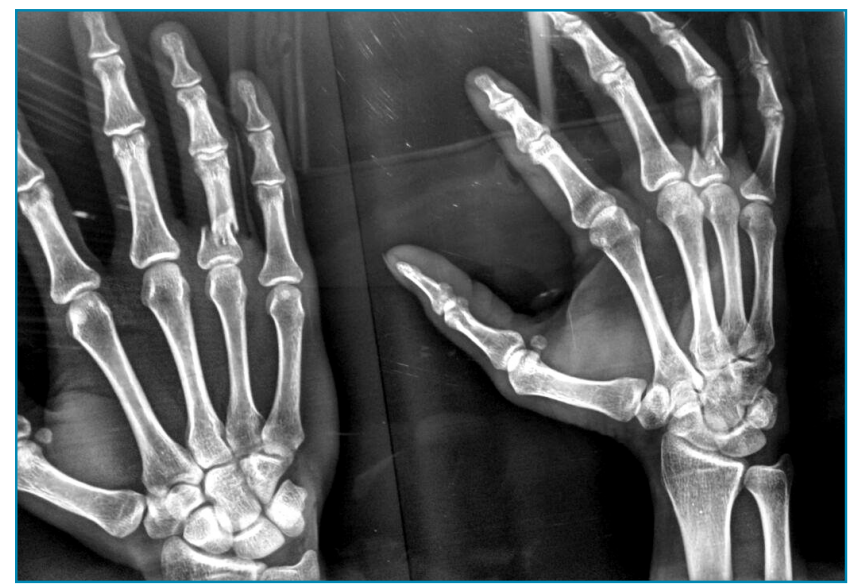

Fig. 1a: Preoperative X ray most common complication in hand injuries and patient can return back to his work at the earliest.

The aim of the study was to evaluate the functional outcome of metacarpal and phalanges fracture after the JESS fixator application and access the usefulness in our set up.

\section{MATERIALS AND METHODS}

The present prospective study includes total number of 38 patients with a diagnosis of fracture of metacarpal and phalanx of hand admitted in Nepal Medical college and Teaching Hospital from 2015 to 2017, who was treated with JESS fixator. Informed consent was obtained by explaining the operative and post-operative complication and all of them were followed up at regular intervals of 2 , 6, 24 weeks and 1 year for clinical and radiological evaluation. The inclusion criteria were skeletally matured patients having unstable, open fracture (Gartlands type I, II), intra articular fractures of metacarpal and phalanx of hand. The patients with stiffness, deformity due to previous injury and those patients who had pathological fracture and crush injury were excluded from the study. The basic components of JESS fixator are Kirschner wires, connecting rods, beta clamp, distraction and compression external fixator.

The fracture reduction was achieved by traction and manipulation under the image intensifier, once reduction was achieved, to maintain reduction JESS fixator was applied, initially by passing at least $2 \mathrm{k}$ wires proximally and 2 distally to the fracture at safe zones. These constructs were connected using connecting rods after the distraction achieved especially in intraarticular fractures. In case of open fracture, initially proper debridement was done followed by JESS fixator application and regular dressing done postoperatively. Antibiotics were given for 48 hours and prolonged in cases of open fracture upto 5 days. Postoperatively patients were advised for the active mobilization of the uninjured fingers immediately. The pin tract

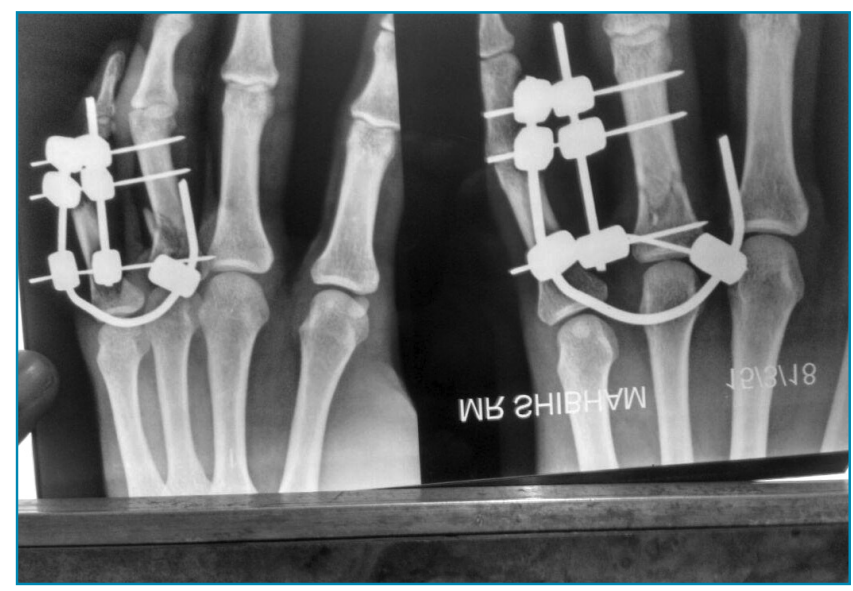

Fig. 1b: Postoperative X ray 
dressing and tightening of the clamps of connecting rods was done regularly. JESS fixator was removed after 6 weeks interval with immediate vigorous mobilization of the joints of hands and wrist was done. The functional outcome after the removal of JESS fixator was assessed by calculating American Society for Surgery of Hand and Total Active flexion (ASSH TAF) was done. ${ }^{9}$

\begin{tabular}{|lc|}
\multicolumn{2}{|c|}{ Table-1: ASSH TAF Score System } \\
\hline Degree of Flexion & Rating \\
TAF from MCP to DIP: Digits 2-5 & \\
$>220$ & Excellent \\
$>180-220$ & Good \\
$<180$ & Fair \\
TAF from MCP to DIP: Thumb & \\
$>120$ & Excellent \\
$>100-120$ & Good \\
$<100$ & Fair \\
\hline
\end{tabular}

\section{RESULTS}

A total of 38 patients with injury meeting the inclusion criteria were studied and analyzed. Among them $31(81.5 \%)$ were males and $7(19.5 \%)$ were females. The patients were in between the age group of 19 to 57 years with an average age of 32.4 years. The rightside hand was involved in $33(86.84 \%)$ patients and 5 (13.36\%) patients had left sided hand involvement.

The most common mode of injury was due to injuries by machinery, which was followed by physical assault (Table-2).

\section{Table-2: Mode of injury}

\begin{tabular}{lcc} 
Mode of injury & \multicolumn{2}{c}{ No. of patients } \\
& $\mathbf{n = 3 8}$ & $\%$ \\
$\begin{array}{l}\text { Injuries by } \\
\text { machinery }\end{array}$ & 17 & 44.74 \\
$\begin{array}{l}\text { Injuries by Road } \\
\text { Traffic Accident } \\
\text { Injuries by Physical } \\
\text { Assault }\end{array}$ & 11 & 28.94 \\
$\begin{array}{l}\text { Injuries by House } \\
\text { hold Activities }\end{array}$ & 8 & 21.05 \\
\hline
\end{tabular}

There were $22(57.89 \%)$ cases of intraarticular fracture and $16(42.11 \%)$ cases were of extraarticular fracture. The maximum number of bony injuries were seen in metacarpal and least in middle phalanx of fingers (Table-3).

The injury associated with open fracture was seen in $24(63.15 \%)$ patients and $14(36.85 \%)$ of them had a close fracture. In open fracture injury, all the wound was healed without any complication. All the fractures were reduced by closed manipulation, none of them required open reduction. Among the 38 patients, all fractures went to union with an average union period of 6 weeks.

\section{Table-3: Bony involvement of injury}

\begin{tabular}{|lcc|} 
Bony Involvement & $\begin{array}{c}\text { No. of patients } \\
\mathrm{n}=30\end{array}$ & $\mathbf{\%}$ \\
Metacarpal & 21 & 55.26 \\
Proximal phalanx & 12 & 31.57 \\
Middle phalanx & 5 & 13.15 \\
Distal phalanx & 0 & 0.0 \\
\hline
\end{tabular}

The mean period of treatment for metacarpal fractures was12 weeks and for phalangeal fractures 16 weeks by which time patients regained full functional activity of hand and returned back to their respective works. There were no cases of axial or rotational deformity was observed. The functional outcome assessed by ASSH-TAF score was excellent in 28 patients, good in 10 patients and none of them had a poor result (Table-4).

\begin{tabular}{|lcc|}
\multicolumn{3}{c}{ Table-4: TAF at 1 year } \\
TAF Grading & Frequency & $\%$ \\
Excellent & 28 & 73.70 \\
Good & 10 & 26.30 \\
Poor & 0 & - \\
Total & 38 & 100 \\
\hline
\end{tabular}

The complication was seen in 9 (23.7\%) cases, superficial pin tract infection and K-wire loosening (Table-5). The superficial pin tract infections were treated with oral antibiotics which was healed in all cases.

\begin{tabular}{|lcc|}
\multicolumn{3}{|c|}{ Table-5: Complications } \\
\hline Complication & Frequency & $\%$ \\
$\begin{array}{l}\text { Superficial pin tract } \\
\text { infection }\end{array}$ & 7 & 77.8 \\
K-wire loosening & 2 & 22.2 \\
Total & 9 & 100 \\
\hline
\end{tabular}

\section{DISCUSSION}

Metacarpal and Phalangeal fractures are common encountered injury, which are often neglected as a minor injury. Most of these fractures can be treated conservatively. ${ }^{10,11}$ James et al reported that closed method used in treatment of unstable fractures had loss of function in $77 \%$ of fingers. ${ }^{12}$ So, unstable, intra 
articular and open fractures operative treatment is indicated as active reduction and stabilization is required to achieve the optimal position for bone healing and to allow early movement. ${ }^{13}$

The unstable fracture requires a stable fixation for healing, whereas fixator provides a stable construct with easy application and quick procedure. The intra-articular fractures are more likely to obtain a better functional result whenever the ligamentotaxis principle is applied through the fixator.

Open fractures are commonly combined with severe comminution, soft tissue damage and wound contamination, application of fixator provides the stability at the fracture site and as well as it is easy for a regular dressing for soft tissue injury leading to both bone and soft tissue healing together. These factors, combined with the ease of placement of JESS fixator, allowing bony healing without further damage to the soft tissue and early rehabilitation make such a JESS fixator a choice of devise for the metacarpal and phalanges fractures.

In our study, injury was seen more in males than in females: male $31(81.5 \%)$ and female $7(19.5 \%)$. This is comparable to other studies. Naidu et al ${ }^{14}$ had 41 (82\%) males and 9 (18\%) females, Parson et a $l^{15}$ had 26 (86.66\%) males and 4 (13.44\%) females and Schuind et $a l^{16}$ had males $21(80.7 \%)$ and females 5 (19.3\%). The predominance of males having hand injury may be due to their type of occupation. This is supported by our study, where the mode of injury is maximum in machinery accidents 17 (44.74\%), road traffic accidents 11 (28.94\%) followed by physical assault 8 (21.05\%). This was comparable to other studies. Naidu et $a l^{14}$ showed maximum injury rate due to road traffic accidents 15 (30\%) followed by machinery 14 (28\%). Parson et a $l^{15}$ showed most injury occurring due to road traffic accidents 11(55\%), fall injury 7 (35\%) and physical assault 2 (10\%).
The average age group was 32.4 years in our study, whereas in Parson et al ${ }^{15}$ study the average age group was 28 years. The involvement of the hand injury is more in younger age group population as there are the one who are more vigorously involved in the daily activities of the life.

There was involvement of injury more in the righthand accounting $(86.84 \%(n=33)$ and left hand $13.36 \%(n=5)$ in our study, which can be compared with the study of Parson et al ${ }^{15}$ where it accounts for $55 \%(n=11)$ of right hand and $45 \%(n=9)$ in left hand. The dominant hand seems to be injured more often.

The average radiological union was achieved in 6 weeks, when the fixator was removed and rehabilitation was started. This finding is similar to the study done by Parson et $a l^{15}$ where average union was seen in 4.8 weeks.

The excellent outcome was seen in $73.70 \%(n=28)$ followed by good in $26.30 \%(n=10)$ according to the ASSH-TAF score. This shows that the patients regain their range of movement of the fingers and were able to perform their activities without any compromise due to the limited motion of the joints.

The superficial pin tract infection was seen in 7 cases $(18.5 \%)$ and loosening of K-wires was observed in $2(5.25 \%)$ cases in our study, whereas Naidu et al ${ }^{14}$ observed K-wire loosening in 8 cases (16\%) and pin tract infection in 7 cases (14\%), Drenth et $a l^{17}$ had 6 cases $(11.5 \%)$ of K-wire loosening.

In conclusion, JESS fixator is cheap, easily available and less technically demanding, provides effective treatment for the metacarpal and phalanges fracture as it provides adequate stability that allows early rehabilitation with soft tissue care and has good functional outcome.

\section{REFERENCES}

1. van Onselen EBH, Karim RB, Joris Hage J, Ritt MJPF. Prevalence and distribution of hand fractures. $J$ Bone Joint Surg 2003; 28B: 491-5.

2. Feehan LM, Sheps SM. Incidence and demographics of hand fractures in British Columbia, Canada: a population-based study. J Hand Surg 2006; 31A: 1068-74.

3. De Jonge JJ, Kingman J, van der Lei B et al. Fractures of the metacarpals: a retrospective analysis of incidence and aetiology and a review of the Englishlanguage literature. Injury 1994; 25: 365-9.

4. Chong KS. Principles in the management of a mangled hand. Indian J Plast Surg 2011; 44: 219-26.

5. Tintle SM, Baechler MF, Nanos GP 3rd, Forsberg JA, Potter BK. Traumatic and trauma related amputations: Part II: Upper extremity and future directions. J Bone Joint Surg Am 2010; 92: 2934-45.

6. Stern PJ. Factures of metacarpals and phalanges. In: Green DP, Hotchkiss RN, Pederson WC, eds. Green's operative hand surgery. 4th edn. Vol. 1. Philadelphia, USA: Churchill Livingstone, 1999, 711-57.

7. Tavassoli J, Ruland RT, Hogan CJ, Cannon DL. Three cast techniques for the treatment of extra-articular metacarpal fractures. Com- parison of short-term outcomes and final fracture alignments. J Bone Joint Surg 2005; 87A: 2196-2201.

8. Freeland AE, Orbay JL. Extra-articular hand fractures in adults: a review of new developments. Clin Orthop 2006; 445: 133-45.

9. Clinical Assessment Committee. Total Active Flexion (TFA) Scale, American Society for Surgery of the Hand (ASSH) report. New Orleans, 1976.

10. Barton N. Conservative treatment of articular fractures in the hand. J Hand Surg Am 1989; 14: 386-90. doi: 10.1016/0363-5023(89)90119-6.

11. Wright TA. Early mobilization in fractures of the metacarpals and phalanges. Can J Surg 1968; 11: 491-8. 
12. James JIP. Fractures of the proximal and middle phalanges of the fingers. Acta Orthop Scand 1962; 32:401-412. doi10.3109/17453676208989599.

13. Freeland AE, Orbay JL. Extraarticular hand fractures in adults: A review of new developments. Clin Orthop Relat Res 2006; 445: 133-45.

14. Naidu KVD. Management of metacarpal and phalangeal fractures with JESS fixator: A prospective study. Int'l J Orthopaed Sci 2018; 4: 3837.
15. Parsons SW, Fitzgerald JA, Shearer JR. External fixation of unstable metacarpal and phalangeal fractures. J Hand Surg Br 1992; 17: 151-5.

16. Schuind F, Noorbergen M, Andrianne Y, Burny F. Comminuted fractures of the base of the first metacarpal treated by distraction-external fixation. J Orthop Trauma 1988; 2: 314-21.

17. Drenth DJ, Klasen HJ. External fixation for phalangeal and metacarpal fractures. J Bone Joint Surg [Br] 1998; 80(B): 227-30. 